\title{
EJA: EDUCAÇÃO DE JOVENS E ADULTOS COMO POLÍTICA EDUCACIONAL INCLUSIVA NO BRASIL
}

Eliana Cristina Rosa*

\begin{abstract}
RESUMO: Este trabalho discutiu a situação da educação de Jovens e Adultos no Brasil. Pretendeu verificar a educação de jovens e adultos, enquanto inclusiva, bem como identificar a acreditação como um dos aspectos relevantes para a melhoria da qualidade do ensino oferecido a comunidade. O estudo de abordagem qualitativa, exploratória, com pesquisa bibliográfica e documental. Dos resultados obtidos destacam-se: as políticas educacionais e documentos legais, garantem a inclusão deste segmento populacional, porém não atendem plenamente as demandas, visto os limitados investimentos financeiros, altos índices de evasão escolar, provenientes de dificuldades sociais, econômicas e do fragmentado processo de ensino e aprendizagem. É necessário criar estratégias efetivas para 0 atendimento das demandas educacionais deste público. Concluiu-se que trabalhar questões educacionais de jovens e adultos deve ser uma das prioridades na agenda educacional das esferas governamentais. O programa EJA se mostra expressivo no campo educacional e necessário em relação às políticas públicas no país. A avaliação e acreditação do Programa é uma das estratégias para a melhoria da qualidade do ensino na busca por equiparar a educação.
\end{abstract}

Palavras-chave: EJA; Políticas Públicas; Inclusão; Acreditação.

ABSTRACT: This paper discussed the situation of the Youth and Adult Education in Brazil. He intended to check the adult education as inclusive as well as identify the accreditation as one of the important aspects to improve the quality of education offered to the community. The study of qualitative, exploratory approach, with bibliographical and documentary research. The results obtained are: educational and legal documents policies, ensure the inclusion of this population segment, but did not fully meet the demands, as the limited financial investment, high rates of school dropouts, from social problems, economic and fragmented process teaching and learning. You must create effective strategies to meet the educational demands of the public. It was concluded that work educational issues of young people and adults should be a priority in the educational agenda of government spheres. The EJA program shows significant and necessary in the educational field in relation to public policies in the country. The evaluation and accreditation of the program is one of the strategies to improve the quality of education in seeking to equate education.

Keywords: EJA; Public Policy; Inclusion; Accreditation.

Mestranda em Educação pela Universidade Lomas de Zamora (Argentina), com especialização em Saúde Coletiva pela Universidade Federal do Triângulo Mineiro (UFTM). 


\section{INTRODUÇÃO}

No Brasil, a educação de jovens e adultos, passou por varias mudanças relacionadas ao cenário educacional, econômico, social e político Compreender a contribuição e efetividade do Programa de Educação de Jovens e Adulto (EJA), como uma política de inclusão propicia melhorias na qualidade educativa das instituições e programas, fomentando uma cultura de avaliação e análise educacional. Faz-se importante ressaltar que: "as Diretrizes Curriculares Nacionais para a Educação de Jovens e Adultos, resolução CNE/CEB n.ำ1/2000, definem a EJA como modalidade da Educação Básica e como direito do cidadão, afastando-se da ideia de compensação e suprimento, assumindo a de reparação, eqüidade qualificação - o que representa uma conquista e um avanço", (BRASIL, 2002).

Desta forma e baseado na definição do EJA enquanto um direito do cidadão, surgem inquietações e questionamentos sobre até que ponto o EJA contribui para a inclusão da população atendida.

Os programas governamentais e educacionais ofertados a população são relevantes para as pessoas como uma das formas de inclusão social, visto que para a entrada no mercado de trabalho, a instrução é um dos fatores principais que direciona jovens, adultos para programas desta natureza. Porém não basta oferecer programas e projetos que atendam o segmento populacional referido. É preciso que estes sejam qualificados e que efetivamente atendam as reais necessidades de educação básica do ponto de vista pedagógico, humano, material, social, entre outros. Para tanto a acreditação - no cumprimento dos critérios mínimos dos cursos e programas ofertados a comunidade significaria melhor qualidade do processo de ensino aprendizagem (ensinagem).

Autores como Jurado (2014) enfatizam em seus estudos a relevancia da avaliação e acreditação no processo de monitoramento da melhoria da qualidade do ensino, pois a avaliação propicia publicamente a qualidade das instituições, cursos, programas e a acreditação fornece a 
sociedade o cumprimento dos critérios mínimos dos cursos e programas ofertados a comunidade.

Marquez (2010, p.148), também aponta [...] a avaliação e acreditação são processos indissociáveis. O processo de avaliação transmite publicamente à sociedade uma mensagem sobre a qualidade de uma instituição ou curso. Já a acreditação fornece à sociedade uma informação relevante sobre se determinado curso cumpre os critérios mínimos de qualidade para o seu reconhecimento.

Os estudos avaliativos contribuem de maneira eficaz no processo da melhora continua das políticas públicas, com efetivas intervenções obtidas, por meio das avaliações, sendo de vital importância para a melhora da pertinência em relação à tomada de decisões pelo Ministério da Educação e do Governo, dentro do sistema educativo nacional de acordo com as demandas da população. Ainda conforme, Nirenberg (2007), apud Diniece (2008, p.07):

La evaluación implica una reflexión, esto es, "tomar distância de la acción para tomar ésta como 'objeto' de análisis, para revisar qué es lo que se está proponiendo o qué se está haciendo o qué se ha hecho, analizar las características de las metodologías de intervención planteadas o desplegadas, y determinar si la orientación es efectivamente hacia la direccionalidad deseable, aclarando cuáles escollos y cuáles facilidades se presentan y cuáles logros se esperan y/o se han obtenido.

Assim a presente pesquisa pretende verificar a educação de jovens e adultos no Brasil, enquanto uma educação inclusiva para aqueles que não se beneficiaram da mesma em sua infância, por falta de oportunidade ou por outras condições adversas, bem como identificar a acreditação como um dos aspectos relevantes para a melhoria da qualidade do ensino oferecido a jovens e adultos. É uma pesquisa de abordagem qualitativa, exploratória; uma investigação bibliográfica e documental. 


\section{MÉTODO}

Tratou-se de uma pesquisa documental, exploratória e qualitativa, elaborada seguindo a proposta de Rodrigues (2006), e ressalta que, a pesquisa bibliográfica pode ser elaborada como um trabalho em si mesmo. A coleta do material deu-se por meio de pesquisa bibliográfica na internet. A produção selecionada foi submetida à leitura analítica, categorizada e subsidiou a elaboração deste manuscrito.

A escolha metodológica justifica-se pela relevância educacional dos documentos analisados, com o conhecimento prévio da importância que o programa exerce na cidadania ativa e produtiva do indivíduo e da sociedade. Conhecer e analisar as contribuições culturais, educacionais e cientificas do passado e da atualidade e explorar novas áreas, onde os problemas não se cristalizaram suficientemente, fomenta novas pesquisas no universo educacional, (UNOESC, 2006).

A pesquisa investigou a educação de jovens e adultos nas bases dos sites do Ministério da Educação, Google Acadêmico, Portal do MEC, livros, revistas educacionais virtuais, Censo Demográfico e artigos correlacionados ao tema proposto.

Após leitura e documentação das informações coletadas, foi realizada a seleção do material, com um total de 59 publicações, tendo como referência filtros de busca. Tais publicações foram selecionadas pelo título, resumo e leitura de textos completos, os quais propiciaram informações suficientes para o referido estudo e constituição das informações na elaboração da pesquisa proposta. Do total de publicações foram selecionadas 24 publicações que fundamentaram a presente investigação, retratando o histórico da educação de jovens e adultos e a relação com a acreditação; inserção de jovens e adultos; evasão e políticas públicas no referido programa. 


\section{DISCUSSÃO}

Em seu histórico a EJA remonta aos tempos coloniais, religiosos e exerceram uma ação educativa missionaria com adultos. Nos períodos imperiais apresentam ações educativas com pouca expressão, pois apenas as elites eram beneficiadas por este direito, (SAMPAIO, 2009),

Muitos movimentos civis mobilizaram a luta contra o analfabetismo e a necessidade de formação de mão de obra qualificada, com atenção a ordem social. O decreto $\mathrm{n}^{0} 16.782 / \mathrm{A}$, de treze de janeiro de mil novecentos e vinte e cinco, o qual ficou conhecido como, Lei Rocha Vaz ou Reforma João Alves, estabeleceu a criação de escolas noturnas para adultos se firmando como questão de política nacional no país, (SAMPAIO,2009).

O processo de alfabetização em todo o seu percurso apresenta uma luta constante, e foi nos anos noventa, século vinte, realizadas conferências internacionais na área da educação. O Brasil, assumiu compromisso com a Declaração Mundial sobre a Educação para todos e nesta época teve início o Fórum Social Mundial e Fórum Mundial de Educação. No ano de 1997 iniciou o Programa Alfabetização Solidária, com a proposta de articulação entre Governo Federal, por meio do Ministério da Educação (MEC), empresas, universidades e prefeituras e somente no ano de 2007 foi realizada uma avaliação com o respectivo redirecionamento do Programa Brasil Alfabetizado para o investimento público federal, estadual e municipal, (SAMPAIO, 2009).

A EJA usufrui de uma especificidade individual de acordo com a Lei 9.394/96, sendo uma modalidade da educação básica nas etapas do ensino fundamental e medio, remetendo-se as diretrizes curriculares nacionais. Dispõe dos seguintes tópicos: fundamentos e funções, bases legais das diretrizes curriculares nacionais da EJA e bases histórico/ legais e atuais na educação de jovens e adultos.

Segundo dados encontrados, o Brasil possui como média nacional a permanência de oito anos na escola, porém esta media apresenta-se em quatro a seis anos, convertendo-se assim em onze anos, estendendo desta forma a duração do ensino fundamental; com o agravante que estes alunos 
deveriam estar cursando o ensino médio, desta forma mantendo e aprofundando a distorção idade/ano. O sistema escola abriga em média 36 milhões de crianças no ensino fundamental, porém continua a reproduzir excluídos nos ensinos fundamental e médio, reproduzindo adolescentes, jovens e adultos sem a escolaridade completa, (PARECER CNE/CEB, 2000).

Dados do PARECER CNE/CEB 11/2000 diz que a: expressão desta realidade são a repetência, a reprovação e a evasão, mantendo-se e aprofundando-se a distorção idade/ano e retardando um acerto definitivo no fluxo escolar. Mesmo assim, deve-se afirmar, inclusive com base em estatísticas atualizadas, que, nos últimos anos, os sistemas de ensino desenvolveram esforços no afã de propiciar um atendimento mais aberto a adolescentes e jovens, tanto no que se refere ao acesso à escolaridade obrigatória, quanto a iniciativas de caráter preventivo para diminuir a distorção idade/ano, (PARECER CNE/CEB, 2000).

O INAF-Indicador de Analfabetismo Funcional (2012), nos mostra seus métodos para definir os conceitos de analfabetismo, definindo assim seus índices, são eles: analfabetos absolutos: 7\% dos brasileiros de 15 a 64 anos - Sujeitos que não conseguem realizar tarefas que envolvam a leitura de simples palavras e frases; analfabetos nível rudimentar: 19\% dos brasileiros de 15 a 64 anos - Sujeitos que desenvolveram a capacidade de localizar uma informação explícita em textos curtos; alfabetismo nível básico: 47\% dos brasileiros de 15 a 64 anos- neste nível os sujeitos podem ser considerados funcionalmente alfabetizados, pois leem e compreendem textos de média extensão, localizam informações, mesmo que seja necessário realizar pequenas inferências.

No entanto, apresentam limitações quando as operações requeridas envolvem maior número de elementos ou relações e o alfabetismo nível pleno: $28 \%$ dos brasileiros de 15 a 64 anos - são capazes de compreender e interpretar elementos usuais da cultura escrita: leem textos mais longos e complexos, relacionando suas partes, comparam e interpretam informações, distinguem fato de opinião, realizam inferências e sínteses. Ainda neste contexto temos que considerar que o Brasil apresenta um movimento 
migratório intenso, com seu auge nos anos de 1960 e 1970 e ainda expressivo nos dias atuais. Inúmeras famílias buscam outros espaços em outras culturas, especialmente nas metrópoles das regiões sul e sudeste, marcando assim uma diversidade cultural e educacional, (COLAVITTO,2010).

O analfabetismo prende as pessoas sem deixá-las decidir por si só, privatizando as escolhas sem dar espaço a liberdade que temos direito, de sermos críticos ou mesmo de opinar nas questões que influenciam a sociedade em que vivemos. Desta forma o programa EJA nos direciona para questões sociais, culturais e financeiras, deixando o antigo discurso de resgate social do passado e se direcionando expressivamente para o campo das políticas públicas e deveres educacionais para com a população.

Identifica-se a EJA como um serviço educacional destinado às pessoas sem estudos ou mesmo sem inserção na vida educacional, porém observa-se uma redução imensa na procura por este ensino, o qual nos leva a analisar o fato de evasão escolar versus um número expressivo de indivíduos sem escolarização adequada, fora do mercado de trabalho em nosso país.

Conforme Catelli (2014, p.01),

O Censo Escolar 2013, divulgados pelo Ministério da Educação, indicam que 3.102 .816 estudantes estão matriculados na educação de jovens e adultos das redes pública estadual e municipal de ensino. Desse total, 2.143.063 $(69,1 \%)$ estão no ensino fundamental e 959.753 (30,9\%) no ensino médio. Dados demonstram redução de $20 \%$ em comparação com 2012, quando foram registradas 3.906 .877 matrículas.

$\mathrm{Na}$ adequação deste ensino no ano de 2007 o governo direcionou investimentos, por meio do Fundo de Manutenção e Desenvolvimento da Educação Básica de Valorização dos Profissionais da Educação (FUNDEB), porém o financiamento de todas as etapas da educação básica não determina que parte dos recursos seja direcionada às salas da EJA, ficando a mesma em segundo plano, (BARROS, 2014).

De acordo com Barros (2014, p.01):

Outro problema é o cálculo do custo anual de um aluno da EJA. O valor mínimo de repasse às escolas previsto pelo FUNDEB é, em média, $20 \%$ inferior ao que se destina a 
estudantes dos anos iniciais do Ensino Fundamental. Os especialistas são unânimes ao afirmar que, para virar esse jogo, é urgente promover uma adequação curricular. Também é essencial garantir aos professores uma formação específica para trabalhar com essa modalidade de ensino, [...] materiais didáticos, também adaptados do Fundamental, devem ser revistos [...], assim como a estrutura física das salas de aula.

E ainda na fala de Cara (2014, p.01),

[...] como a conclusão da educação básica é um direito de todas as cidadãs e de todos os cidadãos, a demanda total da EJA é de 87 milhões de jovens e adultos brasileiros que não completaram seus estudos, o que nos alerta para pensar como estas pessoas estão inseridas em nossa sociedade, segundo dados disponibilizados por Roberto Catelli Jr., coordenador do Programa de Educação de Jovens e Adultos da ONG Ação Educativa.

Considerar uma desigualdade de renda acentuada no Brasil se faz necessário, conforme dados preliminares do IBGE o ano de 2010, o mesmo nos mostra que embora a média nacional de rendimento domiciliar per capita era de $R \$ 668$ reais, $25 \%$ da população recebiam até $R \$ 188$ reais e ainda metade dos brasileiros recebiam até $R \$ 375$ reais, ou seja, menos do que o salário mínimo naquele ano, que era de $R \$ 510$ reais.

Desse público cerca de $70 \%$, deixou de estudar para trabalhar e ajudar na renda familiar, aproximadamente 3,9 milhões de crianças menores de 16 anos, estão trabalhando informalmente no Brasil, reforçando ou mesmo agravando a taxa de repetência escolar, que posteriormente leva ao abandono da mesma e esta situação as exclui da vida estudantil, limitando suas chances de crescimento humano e profissional e agravando questões sociais de capital e trabalho.

Somos um país com uma extensão territorial expressiva e adversa para toda a população, com questões locais a serem tratadas, na sua grande maioria com suas individualidades, ou seja, cada qual com sua necessidade, (IBGE, 2014).

Uma forma de ver a educação popular é a notoria importancia desta inserção social estando retratada na fala de Paulo Freire (1990), "prática cultural para a liberdade" que apresenta uma nova responsabilidade em 
relação à educação, não só popular, mas que se preocupe com o bem estar do indivíduo, não sendo um problema de poucos e sim de todos.

O Brasil teve como meta para o ano de 2015 reduzir pela metade os índices de analfabetismo e ainda como meta ambiciosa "assegurar a todos os brasileiros de 15 anos ou mais, que não tiveram acesso á escola ou dela foram excluídos precocemente, o ingresso, a permanência e a conclusão do ensino fundamental com qualidade". (BARROS, 2014, p.01)

\section{CONSIDERAÇÕES FINAIS}

A educação de jovens e adultos em seu histórico atendeu uma demanda de resgate de excluídos da educação, atualmente tem como foco a educação inclusiva e a inserção educacional e social do público de jovens e adultos.

A exigencia de ter cursado o ensino medio no momento de conseguir um emprego, direciona este público para as escolas na busca de se adequar e ser inserido nas necesidades do mercado, pois a mão de obra qualificada em nosso país não acolhe a demanda. Dentro do propósito da pesquisa, temos como fato a acreditação da EJA, como um dos pontos positivos de programa que visa à inserção da população na vida escolar e educacional em seu histórico e na atualidade. Com questões primordiais a serem trabalhadas, pois a acreditação do programa, ou seja, os criterios mínimos são vistos como necessários e primordiais no contexto da alfabetização nesta modalidade de ensino.

Faz- se urgente à busca de resoluções relativas ao abandono escolar em idade estabelecida e a evasão expressiva deste aluno na EJA, com a atenção ao material didático disponibilizado e a infraestrutura adequada às necessidades deste aluno. Percebe-se também que a adequação curricular se mostra como sendo um fator a ser implementado, pois este é um público com características distintas do ensino inicial escolar. 
Atualmente, o currículo da EJA não passa de uma adaptação dos conteúdos do Ensino Fundamental e ao ignorar as necessidades desse público, o sistema educacional impulsiona a evasão escolar.

Dentre as questões a serem consideradas neste público temos: vulnerabilidade social, ausencia total ou parcial de trabalho e gravidez precoce, índices importantes a serem estudados, os quais são problemas sociais que propiciam todos os anos a muitos alunos desistirem de estudar, deixar a sala de aula temporariamente ou mesmo definitivamente.

Trabalhar questões educacionais de jovens e adultos deve ser uma das prioridades das agendas educacionais em toda esfera governamental. $O$ programa EJA se mostra expressivo no campo educacional e necessário em relação às políticas públicas no país.

Em relação a acreditação desta educação é primordial novas pesquisas no Brasil, como forma de disseminação do conhecimento, pois apresentam poucas informações disponíveis nas bases de dados, as quais promoveriam subsídios para o crescimento e aprimoramento do referido programa de educação jovens e adultos, bem como impulsionaria os pesquisadores envolvidos nesta modalidade de educação a novas pesquisas no campo da acreditação e validação da EJA, impulsionando as políticas públicas.

Desta forma a pesquisa não teve a intenção de esgotar o assunto, ao contrário, pretendeu levantar indicativos para novos estudos, com questões a serem analisadas, que propiciem avaliações aprofundadas dos vieses que envolvem a educação de jovens e adultos, como forma de inserção social e educacional em todo o contexto da comunidade. Acredita-se na relevância deste estudo na investigação das políticas públicas educacionais e sociais, como aspecto de compartilhar e fortalecer a educação no Brasil. 


\section{REFERENCIAS BIBLIOGRÁFICAS}

BARROS A. Erradicar o analfabetismo: uma velha promessa. 2014. Disponivel em: <http://revistaescola.abril.com.br/politicaspublicas/modalidades/erradicar-analfabetismo-velha-promessa-eja>. Acesso em: 10 set. 2014.

BRANDÃO, C. R. Educação popular. 2010. Disponivel em: http://advivo.com.br/blog/paulo-kautscher/educacao-popular. Acesso em: 10 set. 2014.

BRITO K P. Alfabetização e letramento na EJA. Trabalho de Conclusão de Curso (Graduação em Pedagogia) - Faculdade de Educação, Universidade de Brasília, Brasília, 2014.

BRASIL. Ministério da Educação (BR). Secretaria de Educação Fundamental. Proposta Curricular para a educação de jovens e adultos: segundo segmento do ensino fundamental: 5 a 8 série: Introdução / Secretaria de Educação Fundamental, 2002. Disponivel em <https://www.mec.gov.br/>

CARA D. A Educação de Jovens e Adultos (EJA) é tratada de maneira míope e desumana. 2014. Disponivel em:

http://educacao.uol.com.br/colunas/daniel-cara/2014/08/26/o-maior-desafio-dopne-e-a-educacao-de-jovens-e-adultos.htm. Acesso em: 7 out. 2014.

CATELLI R. Educação de Jovens e Adultos.Censo Escolar 2013: Matriculas na Educação de Jovens Adultos. 2013. Disponível em: $<$ http://www.acaoeducativa.org.br/index.php/educacao/50-educacao-de-jovense>. 2014. Acesso em: 7 out. 2014.

CAVALCANTI, M. J. Metodologia para estudo de caso: livro didatico. 5. Ed. Unisul Virtual. Disponível em: <www.unisul.br/wps/portal/home/unisul-virtual>. 2010. Acesso em:16 ago. 2014.

CENSO Escolar. Matrículas na Educação de Jovens e Adultos registra queda de 20\%. 2013. Disponível em:

<http://www.acaoeducativa.org.br/index.php/educacao/50-educacao-de-jovense-adultos/10004807-censo-escolar-2013-matriculas-na-educacao-de-jovens-eadultos-registra-queda-de-20> Acesso em:10 set. 2014.

COLAVITTO N B A, Aparecida L M M. Educação de Jovens e Adultos (EJA): a importância da alfabetização. Revista Eletrônica Saberes da Educação, São Roque, v. 5, n. 1, 2010.

DINIESE.Guía Para Evaluacíon de Programas em Educación. Consejo Federal de Educación. Elaboración:Área de Investigación Coordinadora:Liliana Pascual Magdalena Chiara.27pág.2008. Acesso em:10/09/2014. 
DANHKE,G.L.Investigación Hernandez;COLLADO,Carlos comunicación humana Kegan 1979 .

FREIRE P.; MACEDO, D. Alfabetização: leitura do mundo, leitura da palavra. Rio de Janeiro: Paz e Terra, 1990.

IBGE. Censo Demográfico 2010. Instituto Brasileiro de Geografia e Estatística. Indicadores Sociais Municipais: uma análise dos resultados do universo do Censo Demográfico. 2014.Disponivel em:

$<$ http://www.ibge.gov.br/home/estatistica/populacao/censo2010/indicadores_so ciais_municipais/default_indicadores_sociais_municipais.shtm>.

JURADO J. A. Sistemas de evaluación y acreditación de la educación. Material didatico. Universidad Nacional de Lomas de Zamora - Maestría en Educación, Buenos Aires, 2014.

MARQUEZ M C C. O Novo Sistema de Avaliação e Acreditação do Ensino Superior: impacto, repercuções e beneficios. Revista Universo Contábil, Blumenau, v. 6, n.1, jan. 2010. Disponível em: <www.furb.br/universocontabil>. Acesso em: 10 set. 2014.

PINTO A. V. Sete lições sobre educação de adultos. São Paulo: Cortez, 1993.

PARECER. Despacho do Ministro em 7/6/2000, publicado no Diário Oficial da União de 2000.Seção 1e. Ver Resolução CNE/CEB.2000.Publicada no Diário Oficial da União de 19/7/2000, Seção 1. 2000. Acesso em:15 out. 2014.

RODRIGUES A. J. Metodologia científica. São Paulo: Avercamp, 2006.

SAMPAIO M. N .Educação de Jovens e Adultos: uma historia de complexidades e tensões. Práxis Educacional, Vitória da Conquista. v. 5. n. 7. 2009. Acesso em: 15 out. 2014.

SAMPIERE, Roberto Hernandez; COLLADO, Carlos Fernández; LUCIO, Pilar Baptista. Metodologia da pesquisa. 3. Ed. São Paulo: McGraw-Hill, 2006.

UNOESC. Metodologia Científica: educação a distância. Ardinete Rover (coord.). Disponível em: <www.unoesc.edu.br>. 2006. Acesso em: 5 set. 2014.

UNISUL. Metodologia para elaboração e aplicação de projetos: livro didático. 2 ed. Palhoça. Unisul Virtual. 2007. Disponível em: <www.unisul.br/wps/portal/home/unisul-virtual>. Acesso em: 5 set. 2014. 
UNESCO. Unicef. Pnud, Fnuap: informe subregional de América Latina: Evaluación de Educación para Todos en el año 2000. Santiago do Chile. Unesco, 1999. 